\title{
POTENTIAL LANDSLIDE EARLY DETECTION NEAR WENCHUAN BY A QUALITATIVELY MULTI-BASELINE DINSAR METHOD
}

\author{
Keren Dai ${ }^{1,2, *}$, Gang $\mathrm{Chen}^{3}$, Qiang $\mathrm{Xu}^{1}$, Zhenhong $\mathrm{Li}^{4}$, Tengteng $\mathrm{Qu}^{5}$, Leyin $\mathrm{Hu}^{6}$, Huiyan $\mathrm{Lu}^{2}$ \\ 1. State Key Laboratory of Geohazard Prevention and Geoenviroment Protection, Chengdu University of Technology, Chengdu \\ 610059, China - daikeren17@cdut.edu.cn \\ 2. College of Earth Sciences, Chengdu University of Technology, Chengdu 610059, China \\ 3. Southwest Branch of State Grid Corporation of China(SGCC), Chengdu 641000, China \\ 4. COMET, School of Civil Engineering and Geosciences, Newcastle University, Newcastle upon Tyne NE1 7RU, UK \\ 5. College of Engineering, Peking University, Beijing 100871, China \\ 6. Beijing Earthquake Agency, Beijing 100080, China
}

COMMISSION III, WG III/3

KEY WORDS: Landslide, Early detection, DInSAR, Sentinel-1, Wenchuan

\begin{abstract}
:
Early detection of landslides is important for disaster prevention, which was still very hard work with traditional surveying methods. Interferometric Synthetic Aperture Radar (InSAR) technology provided us the ability to monitor displacements along the slope with wide coverage and high accuracy. In this paper, we proposed a qualitatively multi-baseline DInSAR method to early detect and map the potential landslides. Two sections of China National Highway 317 and 213 were selected as study area. With this method 10 potential landslide areas were early detected and mapped in a quick and effective way. One of them (i.e. Shidaguan landslide) collapsed on August 2017, which was coincident with our results, suggesting that this method could become an effective way to acquire the landslide early detection map to assist the future disaster prevention work.
\end{abstract}

\section{INTRODUCTION}

With a large amount of earth and stones collapsed, landslide could cause significant damage, huge property losses and casualties. Landslide early detection is vital for the disaster reduction and prevention, which could save the loss of life and property, and minimize the impact of landslide to some degree. However landslide early detection was a complex problem worldwide due to the variations of internal and external factors, such as geological conditions, slope structure, and precipitation (Palmer, 2017). To find the pre-failure deformation was supposed to be an effective and important way for landslide early detection and give the early warning in time (Mazzanti et al., 2011; Xu et al., 2011).

The traditional surveying methods, such as total station and GNSS, could provide accurate displacement results on points. In order to find the potential landslide in wide area, these methods are not effective enough due to the low spatial coverage. Interferometric Synthetic Aperture Radar (InSAR) is a new geodetic method that could measure the surface motion based on SAR images at any weather condition with regular interval. It has been widely used in monitoring and mapping landslide with high accuracy and wide coverage (Dai et al., 2016; Herrera et al., 2013; Tomas et al., 2014).

In this paper, we proposed a qualitative multi-baseline DInSAR method (QM-DInSAR) for potential landslide early detection. Two sections of China National Highway 317 and 213 were selected as study area. By this method, the potential landslide area along these highways were early detected qualitatively with Sentinel-1 multi-baselines interferograms acquired during September 2015 to February 2016. As a result, 10 potential landslide area were found. Their location and nearest villages were provided for verification and further monitoring. This method could find the potential landslide in a quick and effective way, which is valuable to assist future disaster prevention work.

\section{METHODOLOGY}

The DInSAR technique provides an image, called differential interferogram, representing the ground motion occurring between the acquisitions with a centimetric accuracy and a decametric resolution (Massonnet et al., 1993). However, excluding the deformation phase there were two main residue phase in one interferogram. Firstly, the DEM error (i.e. the inaccuracy of digital elevation model) would introduce residue topographic phase. Secondly, the variation of atmospheric phase screen (APS) in the two acquisitions would introduce additional phase, which was called atmospheric effect.

In this method, assuming several SLCs covering same area were acquired. Spatial and temporal threshold were applied to select interferograms with good coherence and less topographic error. As a result a large number of interferometric pairs with multibaselines were generated. Specific good interferogram will be selected to find the slope with active differential phase (i.e. alternative potential landslides area).

Among these active slope, their active differential phase were not totally caused by displacements. The residue phase from

\footnotetext{
* Corresponding author
} 
DEM error and APS would be the main error source as described above. Therefore in the next step, we should remove them from the results. As the residue phase caused by DEM error was proportional to spatial baseline, the interferograms with different spatial baselines could be used to remove the active slope caused by DEM error. As the APS is relevant in space and not relevant in time, by the combination of interferograms with different temporal baselines, we can easily find and remove the active slopes caused by APS. Based on the analysis above, the real potential landslide area could be identified. At the same time, the other selected interferograms could be used as cross validation to confirm the final results. Finally, we can acquire the qualitative result of the potential landslide covering wide area. The flowchart of this method was shown in Figure 1.

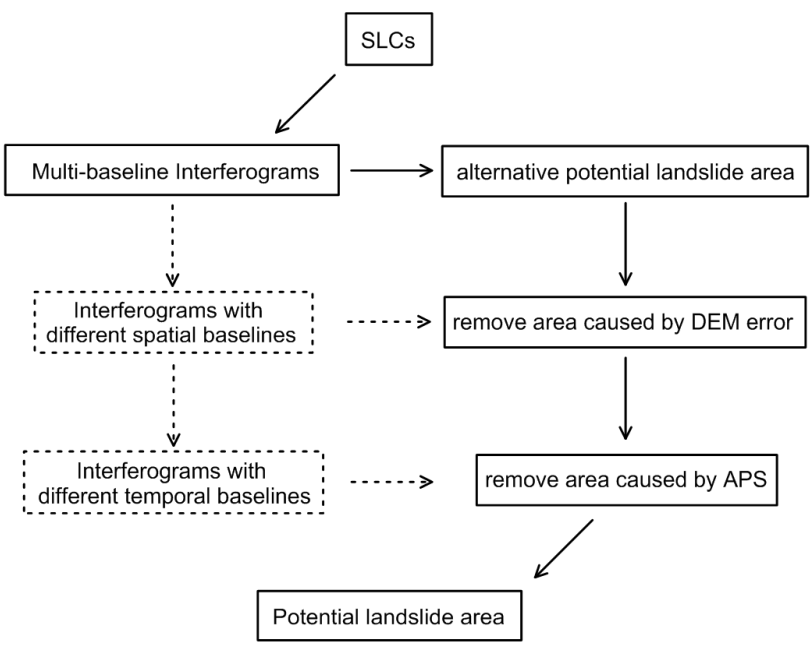

Figure 1. Flowchart of the qualitatively multi-baseline DInSAR method for potential landslide area early detection

\section{STUDY AREA AND DATA SOURCE}

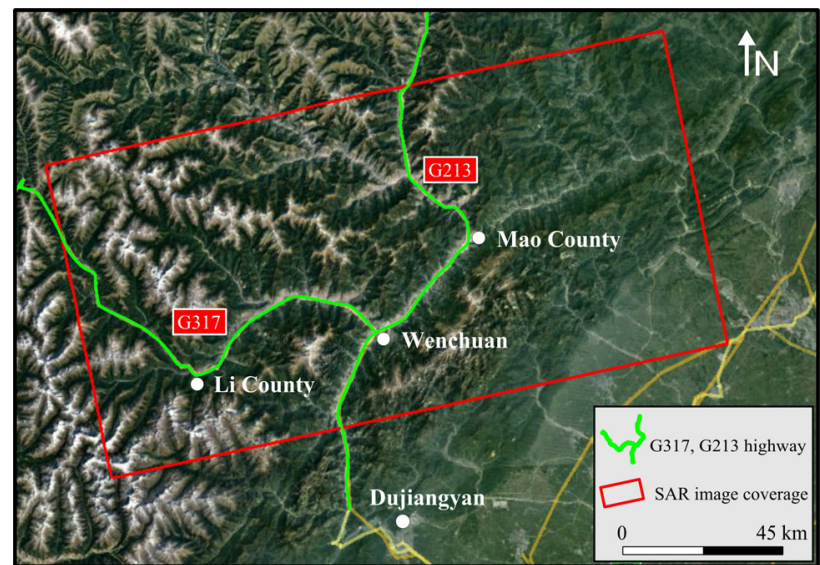

Figure 2. The location of G317, G213 near Wenchuan and the SAR image coverage

The Wenchuan-Li county section of China National Highway 317 (G317) and Wenchuan-Mao county section of China National Highway 213 (G213) were selected as the study area in this paper. G317 runs from Chengdu, Sichuan to Naqu, Tibet, while G213 runs from Lanzhou, Gansu to Mohan, Yunnan. The average altitude of these sections of G317 and G213 highway are about $1700 \mathrm{~m}$, while the nearby mountaintop can reach up to more than $3500 \mathrm{~m}$. These sections of highway were blocked by landslides very often in the past decade, which was in need of wide landslide monitoring for the hazard prevention.

The location of Wenchuan, Mao county and Li County were shown in Figure 2. The G317/G213 highways were marked with green lines, which were located in the Longmen mountainous area in Sichuan province, China, both sides of which were facing numbers of huge slopes.

The Sentinel-1 SAR data in the TOPS mode were used in this paper to investigate the slope displacement along these highways. Sentienel-1 was a constellation of two satellites(i.e. Sentinel-1A and Sentinel-1B), which can provide C-band 200 $\mathrm{km} * 250 \mathrm{~km}$ wide SAR images with medium resolution at 6-12 days repeat cycle. The Sentinel-1 images acquired from September 2015 to February 2016 were used in this study to perform the proposed QM-DInSAR analysis. Its coverage on this area were shown in Figure 2 with red rectangle.

\section{RESULTS AND DISCUSSION}

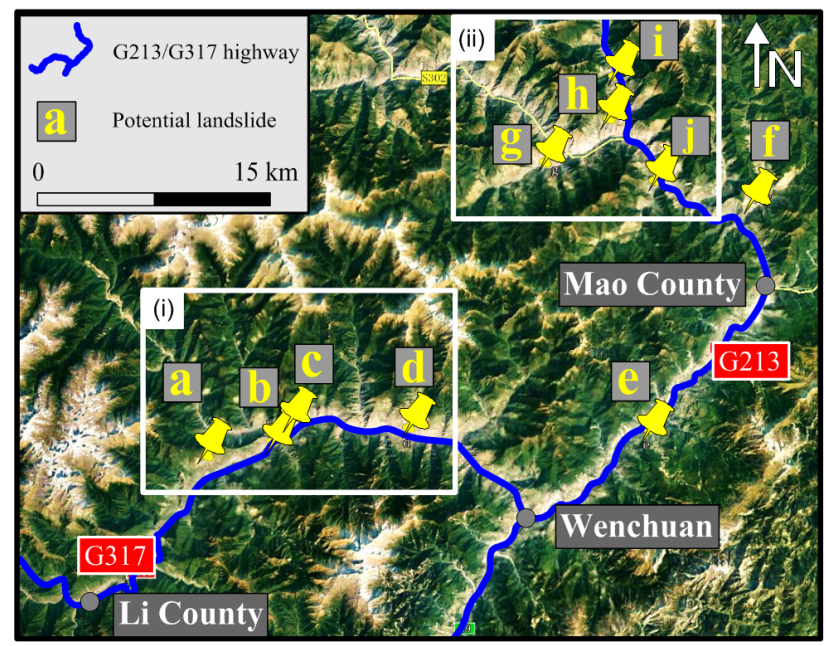

Figure 3. landslide early detection map derived from QM DInSAR method

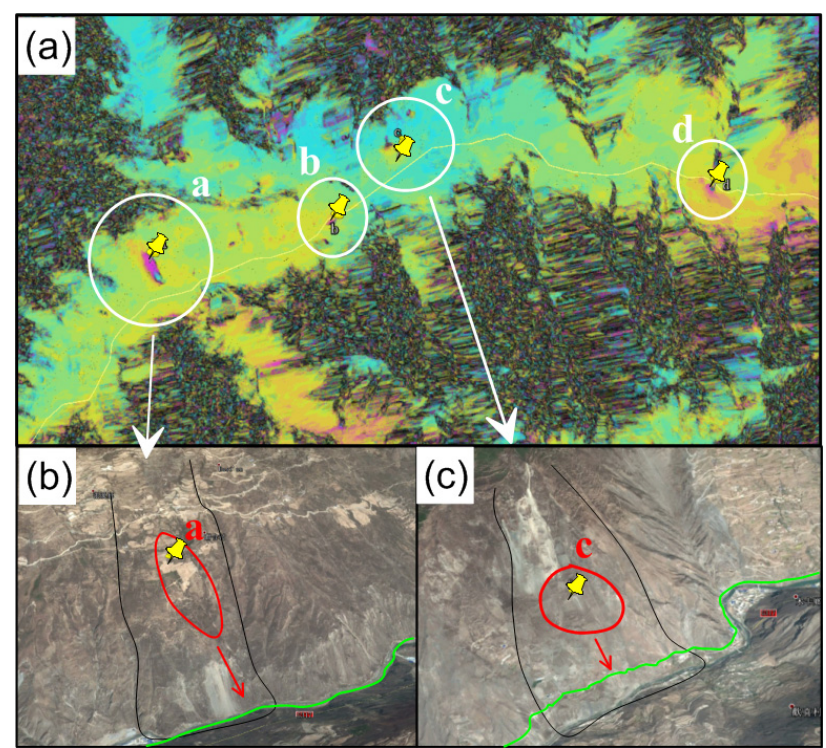

Figure 4. Enlarged (i) area with four potential landslide area. Interferogram(a) and optical images from Google Earth(b)(c) were superposed 
As a result, a qualitative landslide early detection map was acquired, in which ten potential landslide areas with clear displacement were found. Four of them were along the Wenchuan-Li county section of G317 highway and the others were along the Wenchuan-Mao county section of G213 highway. The location of these ten potential landslide and the highways were shown in Figure 3.

The area (i) and area (ii) in Figure 3 were enlarged shown in Figure 4 and Figure 5, respectively. An interferogram (i.e. 20151220-20160113) with good coherence and clear displacement signal were superposed in Figure 4(a) and Figure 5 (a) as base map to help present the size of these potential landslide areas. As shown in Figure 4, in Wenchuan-Li County section of G317 highway, there were four potential landslide, in which ' $a$ ' and ' $c$ ' area were in the north slope of the highway and ' $b$ ' and ' $d$ ' area were in the south slope. Among them ' $a$ ' and ' $c$ ' area were relative big and were enlarged shown in Figure 4(b)(c) with the optical images from Google Earth. The potential collapse of these two places would bring direct threat to the safety of highway. The nearest village of them were Lianhe village and Muka village, respectively.

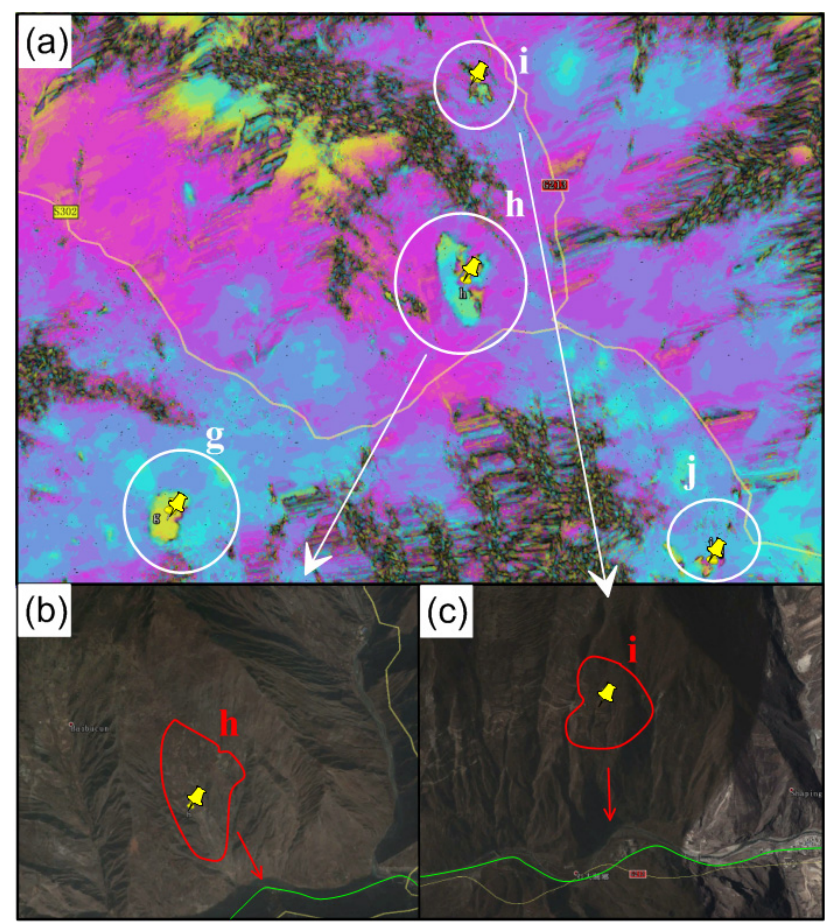

Figure 5. Enlarged (ii) area with four potential landslide area. Interferogram(a) and optical images from Google Earth(b)(c) were superposed

\begin{tabular}{|c|c|c|}
\hline NO. & Nearest village & Location $\left(^{\circ}\right)$ \\
\hline $\mathrm{a}$ & Lianhe & $103.228,31.529$ \\
\hline $\mathrm{b}$ & Mashan & $103.299,31.542$ \\
\hline $\mathrm{c}$ & Muka & $103.322,31.568$ \\
\hline $\mathrm{d}$ & Taoping & $103.451,31.556$ \\
\hline $\mathrm{e}$ & Xiangyang & $103.718,31.554$ \\
\hline $\mathrm{f}$ & Deshengzhai & $103.842,31.777$ \\
\hline $\mathrm{g}$ & Huangcaoping & $103.603,31.807$ \\
\hline $\mathrm{h}$ & Baibu & $103.674,31.848$ \\
\hline i & Shidaguan & $103.860,31.888$ \\
\hline j & Sujiaping & $103.726,31.780$ \\
\hline
\end{tabular}

Table 1 . The details of the 10 potential landslide area
In Wenchuan-Li County section of G317 highway, there were six potential landslide founded and four of them were enlarged shown in Figure 5. The ' $h$ ' and ' $i$ ' area were near Baibu village and Shidaguan village respectively with relative wide movement. It should be noted that the Shidaguan village collapsed at August 2017 (Sichuan News Website, 2017), which was coincident with our early detection results.

The details of these 10 potential landslide were listed in Table 1 . The village information and latitude/longitude of them would provide useful information for the verification and future disaster prevention.

\section{CONCLUSION}

In conclusion, based on the analysis of multi-baseline DInSAR interferograms, landslide early detection map could be acquired by our QM-DInSAR method. Compared to the time series InSAR method, this method was time-saving with small computation. Although it was a qualitative result, it is enough for finding the location of potential landslide and for making hazard prevention strategies. The Shidaguan landslide which collapsed on August 2017 has proved our detection results. With the advantages of time-saving, small computation, wide coverage and high reliability, this method could become an effective way to acquire the landslide early detection map to assist the future disaster prevention work.

\section{ACKNOWLEDGEMENTS}

This work was supported by the research project of State Grid Corporation of China (SGxzzzlwzhbGCJS1700092) and the open fund from State Key Laboratory of Geodesy and Earth's Dynamics (SKLGED2018-5-3-E).

\section{REFERENCES}

Dai, K., Li, Z., Tomás, R., Liu, G., Yu, B., Wang, X., Cheng, H., Chen, J., Stockamp, J., 2016. Monitoring activity at the Daguangbao mega-landslide (China) using Sentinel-1 TOPS time series interferometry. Remote Sensing of Environment 186, 501-513.

Herrera, G., Gutiérrez, F., García-Davalillo, J., Guerrero, J., Notti, D., Galve, J., Fernández-Merodo, J., Cooksley, G., 2013. Multi-sensor advanced DInSAR monitoring of very slow landslides: The Tena Valley case study (Central Spanish Pyrenees). Remote Sensing of Environment 128, 31-43.

Massonnet, D., Rossi, M., Carmona, C., Adragna, F., Peltzer, G., Feigl, K., Rabaute, T., 1993. The displacement field of the Landers earthquake mapped by radar interferometry. Nature 364, 138-142.

Mazzanti, P., Rocca, A., Bozzano, F., Cossu, R., Floris, M., 2011. Landslides forecasting analysis by displacement time series derived from satellite InSAR data: preliminary results. Small 5000, 50,000.

Palmer, J., 2017. creeping earth could hold secret to deadly landslides. Nature 548, 384-386.

Sichuan News Website. 2017. The cars has been safely diverted and advised to return at Shidaguan landslide(Mao County), wit 
hout casualties. http://scnews.newssc.org/system/20170806/000 805474.html

Tomas, R., Li, Z., Liu, P., Singleton, A., Hoey, T., Cheng, X., 2014. Spatiotemporal characteristics of the Huangtupo landslide in the Three Gorges region (China) constrained by radar interferometry. Geophysical Journal International 197, 213-232.

Xu, Q., Yuan, Y., Zeng, Y., Hack, R., 2011. Some new prewarning criteria for creep slope failure. Science China Technological Sciences 54, 210-220. 